\title{
O CONSTITUCIONALISMO UNIVERSAL E A NORMA FUNDAMENTAL DE DIREITO INTERNACIONAL DE HANS KELSEN
}

\section{THE UNIVERSAL CONSTITUTIONALISM AND THE FUNDAMENTAL RULE OF INTERNATIONAL LAW BY HANS KELSEN}

\author{
${ }^{1}$ Gustavo Santiago Torrecilha Cancio \\ ${ }^{2}$ Lívia Gaigher Bósio Campello
}

\section{RESUMO}

A possibilidade de se afirmar teoricamente um constitucionalismo que seja universal é uma questão que há muito vigora no âmbito do Direito Internacional. Entrementes, são recentes os debates que discutem a sua existência normativa prática, apontando seus elementos constitutivos, sua conceituação e sua força normativa na sociedade internacional. É dentro dessa perspectiva que o presente artigo pretende analisar, por intermédio de uma revisão bibliográfica, a dificuldade em se desenvolver meios de preservação do princípio democrático e da igualdade soberana num quadro de produção normativa internacional e sua relação com a teoria da norma fundamental internacional proposta por Hans Kelsen.

PALAVRAS-CHAVE: Direito Internacional; Constitucionalismo Universal; Norma Fundamental Internacional; Força Normativa; Igualdade Soberana

\begin{abstract}
The possibility of theoretically asserting an universal constitutionalism is a longstanding issue in International Law. However, there are recent debates that discuss its practical normative existence, pointing out its constitutive elements, its conceptualization and its normative force in the international society. It is within this perspective that the present article intends to analyze, through a bibliographical revision, the difficulty in developing means of preserving the democratic principle and sovereign equality in a framework of international normative production and its relation with the theory of the international fundamental rule proposed by Hans Kelsen.
\end{abstract}

KEY WORDS: International Law; Universal Constitutionalism; International Fundamental Rule; Normative Force; Sovereign Equality

\footnotetext{
${ }^{1}$ Mestrando do Programa de Pós-Graduação em Direito da Universidade Federal de Mato Grosso do Sul UFMS, Mato Grosso do Sul, MS, (Brasil). E-mail: gustavo_cancio@ hotmail.com.

${ }^{2}$ Pós-doutora em Direito pela Universidade de São Paulo - USP, São Paulo, SP, (Brasil). Professora Adjunta da da Universidade Federal de Mato Grosso do Sul - UFMS, Mato Grosso do Sul, MS, (Brasil). E-mail: livia.gaigher@uol.com.br.
} 


\section{INTRODUÇÃO}

A existência do constitucionalismo global é uma questão que há muito vigora no âmbito do Direito Internacional. O constitucionalismo nasce inegavelmente na esfera interna dos Estados e tardou séculos em sua evolução histórica para de fato se consolidar como fenômeno recorrente na vida política, jurídica e social dos países do globo. Alvo de diversas transformações em sua concepção, o constitucionalismo na atualidade reflete um progressivo alargamento da esfera pública dos direitos fundamentais no interior dos Estados modernos.

A dimensão universalista do direito constitucional moderno é uma constante recente e ainda pouco trabalhada. De fato, existe na atualidade uma constitucionalização do direito internacional, processo que ainda pode ser tido como embrionário, havendo um longo caminho a percorrer.

Uma das transformações mais atuais na busca por essa distensão jurídica das garantias básicas a todos os cidadãos é justamente a busca de universalização desses direitos que seriam inerentes a qualquer ser humano.

Dentro dessa perspectiva, pesaria a favor da existência do constitucionalismo universal a Carta da ONU, tratado constitutivo da Organização das Nações Unidas, tendo em vista que há referência em seu texto à composição da comunidade internacional (povos e governos), ao seu passado (escória da guerra), às suas crenças (direitos humanos fundamentais) e ao seu projeto de futuro (estabelecimento da justiça, progresso econômico e social e autodeterminação dos povos).

Seguindo entendimento semelhante, o argumento de que a Carta da ONU pode produzir efeitos sobre Estados não membros da organização, como ocorre com o art. $2^{\circ}$, $\S 6^{\circ}$, do mencionado diploma, bem como sobre obrigações decorrentes de outros tratados, prevista no art. 103 da Carta da ONU, significaria exceção a dois princípios fundamentais do direito das gentes - res inter alios acta e pacta sunt servanda -, o que indica a existência de um direito superior representado pelo instrumento constitutivo.

Insta pontuar que a ONU tem legitimidade suficiente para que assim se entenda a questão da hierarquia das fontes: atualmente, 193 Estados são membros da ONU, a ampla maioria da sociedade dos Estados, ou seja, a força normativa da Carta decorreria da própria manifestação da vontade da comunidade internacional. 
É certo, contudo, que a tentativa de provar a existência do constitucionalismo universal e, mais ainda, de sua força normativa na sociedade internacional esbarra em diversos desafios. Entre estes obstáculos figuram a ausência de coerência sistêmica no plano jurídico internacional, as tensões advindas das desigualdades econômicas entre os países, as particularidades culturais muitas vezes antagônicas entre as nações, sobretudo quando se considera Ocidente e Oriente e, ainda, a dificuldade em se desenvolver meios de preservação do princípio democrático e da igualdade soberana num quadro de produção normativa internacional, isto é, como manter a vontade geral dos povos neste processo e se limitar o poder, seja hegemônico ou contra-hegemônico.

Tais desafios perpassam, inclusive, pelo debate sobre a efetividade e eficácia do Direito Internacional e de conceitos consagrados nas relações internacionais como o da anarquia internacional, escorando-se no fundamento de que inexiste hierarquia entre os órgãos das Nações Unidas na interpretação da Carta, assim como ao da ausência de freios e contrapesos entre esses mesmos órgãos perante a comunidade internacional e os diplomas constitutivos internos de cada país.

Para o entendimento do estágio atual que vive o constitucionalismo universal, far-se-á, portanto, no presente artigo, uma análise do processo de mundialização do direito, no qual serão pontuadas as possíveis fontes deste processo, de modo a demarcar lhe os limites, enunciando alguns dos seus atributos e traçando pontos de convergência com a possibilidade de se sustentar o constitucionalismo universal.

Não há como deixar de observar, ainda, que tal discussão pode ser observada à luz do pensamento kelsiniano, mormente no que tange a teoria da norma fundamental do Direito Internacional proposta por Hans Kelsen. É com base neste enfoque que o presente artigo pretende desenvolver uma linha comparativa entre ambas as reflexões presentes no âmbito da norma internacional pública.

Para tanto, o procedimento metodológico adotado, de acordo com os critérios assinalados por Sylvia Costant Vergara (2005), quanto aos meios de investigação corresponde à pesquisa bibliográfica, constituída essencialmente de artigos científicos, livros e teses de doutorado sobre a temática em questão e, ainda, e à pesquisa documental, com o acesso a relatórios de pesquisa, documentos oficiais, tratados internacionais, entre outros.

Quanto aos fins, foram utilizados o método descritivo, com o escopo de descrever o fenômeno da força normativa do constitucionalismo universal, expondo suas características e 
estabelecendo correlações entre variáveis, a sua natureza jurídica e a norma fundamental internacional kelnesiana, e o método exploratório, com a finalidade de desenvolver e esclarecer conceitos e ideais afetas ao constitucionalismo universal, provendo critérios de compreensão do fenômeno pesquisado.

\section{O FENÔMENO CONSTITUCIONAL DENTRO DOS ESTADOS: UM BREVE ESCORÇO HISTÓRICO}

Há quem aponte, como o consagrado filósofo político alemão Karl Loewenstein (1970), que o surgimento do constitucionalismo se deu, mesmo que timidamente, na antiguidade, primeiramente com o povo hebreu, que erigiu dentro de um Estado teocrático limitações ao poder político ao assegurar aos profetas a legitimidade para fiscalizar os atos governamentais que extrapolassem os limites bíblicos, e, posteriormente com as CidadesEstados gregas, tidas pelo referido autor como um importante exemplo de democracia constitucional.

Contudo, não há dúvida de que foi somente a partir da Revolução Francesa, deflagrada a partir de 1789, que o mundo passou a conhecer as bases do que hodiernamente se conhece por constitucionalismo. A revolução em comento trazia consigo a "iluminação" e a esperança para um novo Estado Moderno, que pudesse igualar o abismo existente entre as classes sociais, fraternizar com os oprimidos e marginalizados, libertar uma nação da dominação de uma oligarquia e irradiar os direitos fundamentais.

Dentre os muitos ideais e conceitos propagados pela revolução e que fazem referência direta ao estudo do Direito Constitucional, pode-se destacar o pioneirismo do abade Emmanuel Joseph Sieyès. Em sua principal obra publicada em forma de panfleto dias antes da deflagração do movimento revolucionário - Qu'est ce qu'est le Tiers État? -, Sieyès faz uma abordagem crítica sobre a importância do Terceiro Estado dentro da conjuntura francesa da época.

Muito influenciado pelo pensador iluminista Jean-Jacques Rosseau, Sieyès levanta e responde a três questões clássicas em seu discurso: "O que é o Terceiro Estado? Tudo. O que tem sido até agora na ordem política? Nada. O que pede? Ser alguma coisa”. Atrás do caráter político e social intrínsecos a tais questionamentos, nota-se uma linha jurídica que é utilizada até hoje nos ensinamentos de Direito Constitucional: o poder constituinte.

Revista Brasileira de Direito Internacional le-SSN: 2526-0219| Curitiba | v. 2 | n. 2 | p. 154 - 172 | Jul/Dez. 2016. 
Dentro dessa ideia, infere-se que a concepção de poder constituinte para Sieyés está relacionada com o conceito de poder originário, autônomo e onipotente. Diante disso, o poder constituinte se origina primeiramente como forma de realizar uma luta contra o Estado monárquico absolutista que dominava a França desde o declínio do feudalismo.

Sieyès explica, a partir da teoria do poder constituinte, que a nação (entendida não como uma emoção ou como algo metafísico, mas sim como uma categoria política prática) é quem possui a titularidade do exercício desse poder constituinte (uma vez que ela é o instrumento direto da ideia de direito) e, acima de tudo, esse poder, como já foi dito, é originário e soberano. Dessa forma, a nação, vista por Sieyès como sendo o Terceiro Estado na França - já que o Primeiro Estado era formado pelo clero e o Segundo Estado pela nobreza - estaria livre para criar uma Constituição, uma vez que não se sujeitaria mais a formas, limites e condições impostas por regimes totalitários e que já preexistiam.

O século XVIII, portanto, cria uma situação favorável para o surgimento para um novo referencial concreto do poder soberano do Estado com o constitucionalismo. Com isso, a substituição o rei teocrático do Ancien Régime por uma nova Constituição escrita ganha divulgação universal com a revolução.

Trazendo tal modelo constitucional para a atualidade, o teórico Uadi Lammêgo Bulos (2009) aponta que na contemporaneidade há um chamado "totalitarismo constitucional", ou seja, os textos constitucionais sedimentam um importante conteúdo social e programático (normas a serem cumpridas e atingidas pelos Estados), incorporando aspectos de um constitucionalismo globalizado, que busca difundir a ideia de proteção aos direitos humanos e de propagação para todas as nações.

Em consonância com o que assinala Dalmo de Abreu Dallari (2009), três grandes objetivos conjugados resultaram no constitucionalismo, a saber: a afirmação da supremacia do indivíduo, a necessidade de limitação do poder dos governantes e a crença nas virtudes da razão, apoiando a busca da racionalização do poder.

A história do constitucionalismo, segundo Luigi Ferrajoli (2013), é a história de um progressivo alargamento da esfera pública dos direitos. Uma história não teórica, mas social e política, tendo em vista que todos os direitos foram conquistados em rupturas institucionais (nas revoluções, americana e francesa, nos movimentos oitocentistas, nas lutas operárias, feministas, pacifistas e dos ecologistas do século passado). Assim, segundo Ferrajoli

Todas as diversas gerações de direitos correspondem a outras tantas gerações de movimentos revolucionários: das revoluções liberais contra o absolutismo 
que regia os séculos passados [...]. Daquela história faz parte também a extensão, ainda embrionária, do paradigma constitucionalista ao direito internacional. Também a história das relações internacionais foi criada com a instituição da ONU e das Convenções Internacionais de Direitos Humanos, uma ruptura da época: a ruptura do antigo regime internacional nascido três séculos antes, no Pacto de Westfália, fundado sobre o princípio da soberania absoluta dos Estados e junto à sua falência com a tragédia das duas guerras mundiais (FERRAJOLI, 2013, p. 02).

Não é custoso notar que o constitucionalismo teve, quase como regra, um caráter revolucionário. Sobre esse aspecto, não há como fugir da reflexão trazida por Rudolf Von Ihering em sua importante obra A Luta pelo Direito.

Isso porque Ihering não hesita em afirmar que todos os direitos da humanidade foram conquistados pela luta, tendo em vista que todo e qualquer direito, seja o direito de um povo, seja o direito do indivíduo, só se afirma por uma disposição ininterrupta para a luta. Nesse sentido, o mencionado autor conclui com propriedade que

O fim do direito é a paz, o meio de que se serve para consegui-lo é a luta. Enquanto o direito estiver sujeito às ameaças da injustiça - e isso perdurará enquanto o mundo for mundo -, ele não poderá prescindir da luta. A vida do direito é a luta: luta dos povos, dos governos, das classes sociais, dos indivíduos (IHERING, 2009, p. 27).

Dentro dessa perspectiva, conclui-se que o constitucionalismo pode ser visto como um fenômeno, não somente sob a ótica jurídica, mas também social, política e ideológica, por intermédio do qual emanam as constituições nacionais, em sentido mais restrito. De outro vértice, como se verá adiante, em aspectos universais, constitui-se como forma de estabelecimento de normas fundamentais de um ordenamento jurídico que possa disciplinar a sociedade internacional.

\section{O MODELO CONSTITUCIONAL NA ATUALIDADE}

A passagem do século XX para o século XXI trouxe consigo uma nova perspectiva em relação ao constitucionalismo, não mais atrelando tal conceito apenas à ideia de limitação do poder político, mas, sobretudo, na busca pela eficácia da Constituição e de seu conteúdo material. Tal fenômeno é chamado pela doutrina de neoconstitucionalismo, constitucionalismo pós-moderno ou, ainda, pós-positivismo.

Revista Brasileira de Direito Internacional le-SSN: 2526-0219| Curitiba | v. 2 | n. 2 | p. 154 - 172 | Jul/Dez. 2016. 
José Joaquim Gomes Canotilho elucida que o constitucionalismo moderno representa uma técnica específica de limitação do poder com fins garantísticos: "o conceito de constitucionalismo transporta, assim, um claro juízo de valor. É, no fundo uma teoria normativa da política, tal como a teoria da democracia ou a teoria do liberalismo" (CANOTILHO, 2003, p. 51).

O fenômeno neoconstitucional, de acordo com Luiz Roberto Barroso (2010), implica na irradiação dos valores abrigados nos princípios e regras da Constituição por todo o ordenamento jurídico, notadamente por via da jurisdição constitucional, em seus diferentes níveis.

A aplicabilidade direta da Constituição a diversas situações, a inconstitucionalidade das normas incompatíveis com a Carta Constitucional e, sobretudo, a interpretação das normas infraconstitucionais conforme a Constituição, circunstância que irá conformar-lhes o sentido e o alcance. Barroso conclui, assim, que tal fenômeno atual do Direito Constitucional potencializa a importância do debate acerca do equilíbrio que deve haver entre supremacia constitucional, interpretação judicial da Constituição e processo político majoritário.

Nota-se que o modelo normativo neoconstitucional não é mais caracterizado como meramente descritivo, mas sim axiológico. É a partir desse aspecto que Walber de Moura Agra (2008) entende que há diferenças entre o constitucionalismo moderno e o neoconstitucionalismo. Se no primeiro a distinção entre normas constitucionais e infraconstitucionais era apenas hierárquica, no segundo a diferença também é axiológica. Outrossim, no constitucionalismo moderno, o caráter ideológico possuía apenas o escopo de limitar o poder, ao passo que, no neoconstitucionalismo, o seu elemento ideológico é o de concretizar os direitos fundamentais.

A partir dessa análise, Ana Paula de Barcellos, em seu artigo Neoconstitucionalismo, direitos fundamentais e controle das políticas públicas, atesta que o neoconstitucionalismo, além de consolidar as premissas na esfera teórica do constitucionalismo, busca concretizar tais preceitos na prática. Verifica-se essa discussão na eficácia jurídica dos princípios constitucionais, nas possibilidades de omissões legislativas e na efetivação técnica das noções de normatividade, superioridade e centralidade da Constituição.

Em outros termos, percebe-se que a partir do momento em que os axiomas são constitucionalizados, o grande desafio do neoconstitucionalismo passa a ser encontrar mecanismos para sua efetiva concretização. 


\section{O CONSTITUCIONALISMO EM SEU ESTÁgIO GLOBAL: ORIGEM E CONCEITO}

A deflagração da Primeira Guerra Mundial em 1914 em conjunto com o surgimento de uma teoria social do Estado criada como obstáculo aos abusos humanitários decorrentes das omissões que o simples Estado de Direito Liberal apresentava na concretização dos direitos fundamentais, marcaram a necessidade de flexibilização do direito nacional.

Já na primeira metade do século XX iniciou-se, assim, a necessidade de se erigir um núcleo constitucional que fosse quase uníssono entre os países, mormente entre os ocidentais, e que exigisse uma postura mais proativa do ente estatal na efetivação dos direitos sociais, ao contrário dos textos anteriores, que se limitavam a manter um campo de força em favor unicamente do indivíduo contra potenciais violações do Estado. É nessa conjuntura, por exemplo, que surge a Organização Internacional do Trabalho (OIT), criada em 1919, considerada por Marcelo Dias Varella (2005) o ponto de partida da expansão e prevalência das normas internacionais sobre o direito interno.

Em seguida, e ainda no interregno entre guerras, a Sociedade das Nações, criada com o propósito de tratar da resolução dos conflitos pelo diálogo, evitando a guerra, foi pensada tomando por base a proposta de paz conhecida como Quatorze Pontos ${ }^{3}$, feita pelo então presidente americano Woodrow Wilson, em mensagem enviada ao Congresso dos Estados Unidos em janeiro de 1918. O pacto para a criação da Sociedade das Nações constituiu os trinta primeiros artigos do Tratado de Versalhes ${ }^{4}$. O Senado Americano, porém, não ratificou o tratado, e, por consequência, os Estados Unidos da América não se tornaram membros da Liga das Nações, fato que precipitou o seu enfraquecimento e contribuiu para o seu fracasso, estampado com a eclosão da Segunda Guerra Mundial, em 1945.

A segunda grande guerra do século XX trouxe, além da descrença no arranjo internacional dos Estados por meio da Liga das Nações, uma intensificação da necessidade de

\footnotetext{
${ }^{3}$ Os Quatorze Pontos foram são 14 proposições criadas para a reconstrução europeia após a Primeira Guerra Mundial e possuíam o escopo de garantir a paz e evitar novos confrontos motivados pela vingança ou interesses políticos e econômicos.

${ }^{4}$ O Tratado de Versalhes (1919) foi um tratado de paz assinado pelas potências europeias que pôs fim oficialmente à Primeira Guerra Mundial. O tratado foi assinado como uma continuação do armistício de Novembro de 1918, em Compiègne, que tinha posto um fim aos confrontos. O principal ponto do tratado determinava, em síntese, que a Alemanha aceitasse todas as responsabilidades por causar a guerra e que fizesse reparações às nações da Tríplice Entente.
}

Revista Brasileira de Direito Internacional le-SSN: 2526-0219| Curitiba | v. 2 | n. 2 | p. 154 - 172 | Jul/Dez. 2016. 
atribuição de capacidade normativa pelos países aos organismos internacionais, até então esquecidos ou pouco utilizados pela sociedade global.

O emblemático ano de 1945, com o fim da Segunda Guerra Mundial e o advento Carta das Nações Unidas, instrumento constitutivo da Organização das Nações Unidas, é um marco significativo tanto para o direito internacional contemporâneo quanto para as relações internacionais. Conforme elucida Álvaro Osório do Valle Simeão é "o início de uma capacidade normativa que tem por esteio político não o poder soberano de um Estado, mas a conjugação de vontades nacionais voluntárias na tentativa de coordenar ações mínimas para garantir a paz e a segurança mundiais" (SIMEÃO, 2008, p. 03).

As duas guerras mundiais chamam, portanto, a atenção da comunidade internacional de que os direitos humanos fundamentais (entendidos, por muitos, como direitos naturais) extrapolam o poder de positivação estatal.

Diante o exposto, a concepção de constitucionalismo universal agrega conceitos tanto do Direito Constitucional quanto do Direito Internacional. A fim de bem elucidar a relação entre essas áreas do direito público que compõem a base teórica do constitucionalismo global, pode-se representá-las como círculos não concêntricos que se sobrepõem em alguma medida (ver Figura 01 abaixo).

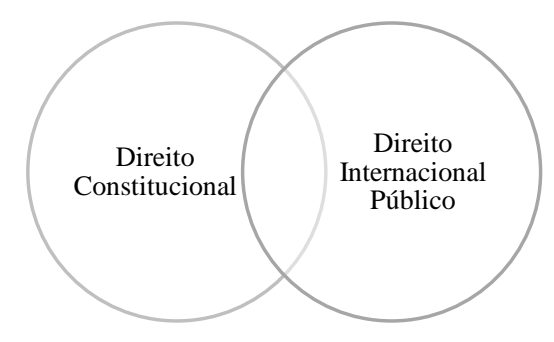

Figura 01: círculos não concêntricos representativos do Direito Constitucional e do Direito Internacional Público.

$\mathrm{O}$ ponto de toque entre ambos é exatamente onde reside o conceito de constitucionalismo universal. Com efeito, em virtude de já ter sido traçado nos itens 01 e 02 os principais aspectos acerca do Direito Constitucional no que se refere ao constitucionalismo, cabe agora analisar alguns elementos que fundamentam o Direito Internacional Público e o caráter universal das normas jurídicas. 
Nessa senda, Francisco Rezek elucida que o Direito Internacional Público, também conhecido como direito das gentes ${ }^{5}$, é "um sistema jurídico autônomo, onde se ordenam as relações entre Estados soberanos, [...] o qual repousa sobre o consentimento" (REZEK, 2011, p. 27).

Valerio de Oliveira Mazzuoli entende que o Direito Internacional Público poderia ser conceituado, de forma sintética, como a disciplina jurídica da sociedade internacional. Em uma definição mais abrangente, o mencionado autor aponta que

O Direito Internacional Público pode ser conceituado como o conjunto de princípios e regras jurídicas (costumeiras e convencionais) que disciplinam e regem a atuação e a conduta da sociedade internacional (formada pelos Estados, pelas organizações internacionais intergovernamentais e também pelos indivíduos), visando alcançar as metas comuns da humanidade e, em última análise, a paz, a segurança e a estabilidade das relações internacionais. (MAZZUOLI, 2011, p. 63)

Percebe-se, desse modo, que o Direito Internacional Público objetiva regular por meio de normas jurídicas as relações internacionais, sendo, assim, apenas um dos componentes do cenário internacional. Igualmente, o DIP, como, de modo geral, todo ramo do Direito, está intrinsecamente ligado ao meio social que pretende regular, nesse caso, a sociedade internacional.

É com fulcro nessas premissas, em conjunto com os preceitos de Direito Constitucional anteriormente apresentados, que se insere o constitucionalismo universal em uma intersecção das duas áreas. O conceito de constituição global, portanto, não seria outra coisa que não fosse o corolário de uma sequência natural de circunstâncias, incluindo aspectos conceituais, ligando-se, assim, à concepção histórico-universal de Constituição.

Nessa esteira, o jurista português Paulo Ferreira da Cunha em seu ensaio denominado Do Constitucionalismo Global, entendendo que a dimensão universalista do direito constitucional moderno é uma constante, se posiciona no sentido de que o constitucionalismo universal funda-se sobre valores e princípios constitucionais gerais, também eles globalizados, sendo um dos primeiros exemplos desta universalização a busca da felicidade ${ }^{6}$.

Cunha continua seu raciocínio concluindo que

\footnotetext{
${ }^{5}$ Expressão, utilizada até hoje no sentido de direito das nações ou dos povos, mas que vigorava como principal até o surgimento da expressão "Direito Internacional”, cunhado pelo jurista inglês Jeremy Bentham em 1780.

${ }^{6}$ A chamada pursuit of happiness, já presente na declaração de independência dos EUA.
}

Revista Brasileira de Direito Internacional le-SSN: 2526-0219| Curitiba | v. 2 | n. 2 | p. 154 - 172 | Jul/Dez. 2016. 
O direito constitucional global é, assim, muito mais vasto e muito mais complexo que o seu pai, o direito constitucional que se apresentava como estritamente nacional (embora já tivesse um fundo comum nos princípios, muitas vezes), e que o seu avô, o direito político. O novo direito constitucional do mundo globalizado tem um novo rosto. Começa por ser muito mais técnico (e implica assim um procedimento e um processo constitucionais subtis), e é assim mais eficaz. O constitucionalismo global é uma ideia dinâmica. Ele fará o seu caminho, com as mesmas dificuldades e as mesmas esperanças que a globalização pacífica e intercultural. Não deve nunca tratar-se de uma globalização uniformizadora, mas de uma globalização que respeite as diferenças (CUNHA, 2010, p. 09-10).

Em outros termos, o constitucionalismo global, a partir de uma visão neoconstitucional, seria um conjunto de princípios e normas institucionalizadas no âmbito internacional que regulam as relações de coexistência e cooperação entre Estados, limitando o poder e a soberania destes - uma vez que são dotados de diferentes graus de desenvolvimento socioeconômico e de poder -, e, além disso, implicando na irradiação desses valores abrigados em um diploma jurídico internacional por todo o ordenamento jurídico mundial.

\section{DIPLOMAS JURÍDICOS COMO FORMA DE EXPRESSÃO DO CONSTITUCIONALISMO GLOBAL}

O processo de universalização e internacionalização dos direitos humanos é um fenômeno que pode ser considerado extremamente recente na história do direito, com delineamentos mais visíveis a partir do término da Segunda Guerra Mundial.

Foi nesse contexto que, em 1945, com o fim da Segunda Guerra Mundial (1939-1945), a Organização das Nações Unidas foi criada, materializando, após o já mencionado fracasso da Liga das Nações, o desejo por uma comunidade internacional pacífica e justa. Destarte, até a atualidade, a ONU aparece no cenário internacional como o único organismo com a legitimidade de uma associação universal de Estados, cujos campos de atuação abrangem a segurança internacional, o desenvolvimento econômico e social, a proteção dos direitos humanos e a proteção do meio ambiente (TAYLOR; CURTIS, 2006).

O seu instrumento constitutivo, a Carta das Nações Unidas, foi assinada por 50 (cinquenta) países em São Francisco, no dia 26 de Junho de 1945, após o encerramento da Conferência das Nações Unidas sobre Organização Internacional, estando em vigor desde 24

Revista Brasileira de Direito Internacional le-SSN: 2526-0219| Curitiba | v. 2 | n. 2 | p. 154 - 172 | Jul/Dez. 2016. 
de Outubro daquele mesmo ano. Foi incorporada ao ordenamento jurídico interno brasileiro pelo Decreto $\mathrm{n}^{\circ} 19.841$, de 22 de outubro de 1945.

Como destaca Flávia Piovesan (2009), se no século XIX, com o constitucionalismo, inicia-se o processo de introdução nas Constituições dos Estados das declarações de direitos, a partir do pós-guerra um segundo impacto é notado. Nessa conjuntura, o anseio por uma ação internacional que fosse mais eficiente para a proteção dos direitos humanos impulsionou o fenômeno de internacionalização desses direitos e ensejou na deflagração da sistemática normativa de proteção internacional, que torna possível, por exemplo, a responsabilização do Estado no cenário global, quando as instituições nacionais se mostram falhas ou omissas na tarefa de proteger os direitos humanos.

Dentro dessa perspectiva, cumpre analisar as disposições que figuram na Carta da ONU e comprovam tal processo de constitucionalização do Direito Internacional, a começar pelo preâmbulo do tratado constitutivo.

A referência no texto preambular à composição da comunidade internacional (povos e governos), ao seu passado (escória da guerra), às suas crenças (direitos humanos fundamentais) e ao seu projeto de futuro (estabelecimento da justiça, progresso econômico e social e autodeterminação dos povos) constitui uma expressão do constitucionalismo universal, ou seja, normas essenciais que cada ordenamento jurídico nacional deveria possuir para estar em harmonia com os princípios que regem a sociedade internacional.

Em consonância com o que elucida Mazzuoli (2011), a Carta da ONU contribuiu enormemente para a formação de um constitucionalismo universal, ao estabelecer nos termos do art. $1^{\circ}, \S 3^{\circ}$, dentre seus objetivos, os preceitos da manutenção da paz e da segurança internacionais; a cooperação internacional para a solução de problemas econômicos, sociais, culturais ou de caráter humanitário; e o respeito aos direitos humanos e liberdades fundamentais para todos, sem distinção de raça, sexo, língua ou religião.

Na mesma linha, o art. 55 do mencionado diploma jurídico internacional, ao prever que os Estados-membros das Nações Unidas devem promover a proteção dos direitos humanos e as liberdades fundamentais, consolida o movimento de mundialização de tais garantias coletivas, a partir do consenso de nações que elevam a consecução desses direitos com fulcro nos escopos das Nações Unidas.

O diploma constitutivo da ONU apresenta, ainda, em seu artigo art. $2^{\circ}, \S 6^{\circ}$, mais uma demonstração da sua superioridade normativa frente aos demais tratados internacionais. 
Nestes termos, tal dispositivo prevê que Organização das Nações Unidas fará com que os Estados que não são membros da ONU ajam de acordo com esses princípios previstos no diploma - tais como o da igualdade soberana dos membros, cumprimento de boa-fé das obrigações e solução pacífica de controvérsias - em tudo quanto for necessário à manutenção da paz e da segurança internacionais

Cumpre destacar que o conteúdo de tais normas no ordenamento jurídico internacional importa em uma exceção a dois princípios fundamentais do direito das gentes - res inter alios acta e pacta sunt servanda -, o que indica, em mais uma oportunidade, a existência de um direito superior representado pelo instrumento constitutivo.

As duas expressões latinas citadas que significam, respectivamente, que os atos dos contratantes não aproveitam nem prejudicam a terceiros e que o que foi pactuado deve ser cumprido, são ambas regras resultantes do consentimento perceptivo da comunidade internacional. Contudo, tais princípios não são absolutos e, como visto, deverão ser afastados em um eventual conflito com os mencionados dispositivos da Carta das Nações Unidas.

Vista de outro aspecto, não há como não apresentar a crítica trazida por Piovesan (2009) acerca da fragilidade da Carta das Nações Unidas em apresentar uma definição precisa sobre o que sejam direitos humanos e liberdades fundamentais, uma vez que a referida Carta adotou uma linguagem vaga e imprecisa para conceituar tais garantias.

Com efeito, fez-se nascer no espectro da comunidade internacional a vontade de aclarar o significado de tais expressões, o que foi materializado três anos após a criação da ONU, com a proclamação da Declaração Universal dos Direitos Humanos, em 1948.

Constituindo-se como um dos principais diplomas internacionais que representam a essência do constitucionalismo global, a Declaração Universal dos Direitos Humanos foi adotada pela resolução 217-A, da Assembleia Geral das Nações Unidas em 10 de dezembro de 1948. Um dos seus objetivos precípuos pode ser expressado por um trecho de seu preâmbulo, tendo em vista que a própria Assembleia Geral proclamou que a referida declaração

[...] tem como o ideal comum ser atingido por todos os povos e todas as nações, com o objetivo de que cada indivíduo e cada órgão da sociedade, tendo sempre em mente esta Declaração, se esforce, através do ensino e da educação, por promover o respeito a esses direitos e liberdades, e, pela adoção de medidas progressivas de caráter nacional e internacional, por assegurar o seu reconhecimento e a sua observância universais e efetivos, tanto entre os povos dos próprios 
Estados-Membros, quanto entre os povos dos territórios sob sua jurisdição. (ONU, 1948).

Segundo Piovesan, a Declaração Universal “[...] vem definir e fixar o elenco dos direitos e liberdades fundamentais a serem garantidos" (PIOVESAN, 2009, p. 159). Já Norberto Bobbio, assinala que tal compilação de direitos inserida na declaração representa a “manifestação da única prova através da qual um sistema de valores pode ser considerado humanamente fundado e, portanto, reconhecido: e essa prova é o consenso geral acerca da sua validade" (BOBBIO, 2004, p. 46).

Nessa linha, Bobbio entende que a Declaração Universal pode ser acolhida como a maior prova histórica até hoje dada do consensus omnium gentium sobre um determinado sistema de valores, uma vez que

[...] agora esse documento existe: foi aprovado por 48 Estados, em 10 de dezembro de 1948, na Assembleia Geral das Nações Unidas; e, a partir de então, foi acolhido como inspiração e orientação no processo de crescimento de toda a comunidade internacional no sentido de uma comunidade não só de Estados, mas de indivíduos livres e iguais (BOBBIO, 2004, p. 47).

Tendo como fundamento a dignidade da pessoa humana, a Declaração Universal dos Direitos Humanos consagra os valores básicos universais de ordem pública mundial fundada no respeito à pessoa humana, titular de direitos iguais e inalienáveis. Nasce, assim, como um "código de conduta mundial para dizer a todo o planeta que os direitos humanos são universais, bastando a condição de ser pessoa para que se possa vindicar e exigir a proteção dos direitos humanos, em qualquer ocasião e em qualquer circunstância” (MAZZUOLI, 2011, p. 786).

Assim, a Declaração introduz a concepção contemporânea de direitos humanos, caracterizada pela universalidade, uma vez que clama pela extensão universal dos direitos humanos, sob a crença de a condição de pessoa ser o requisito único para a dignidade e titularidade de direitos.

Conclui-se, a partir do que foi apresentado, que, tendo como base a conceituação de constitucionalismo (ver itens 01 e 02), que a sociedade internacional reunida buscou estabelecer, por meio dos supratranscritos diplomas jurídicos, princípios e normas fundamentais para a construção de um constitucionalismo que alcance toda a sociedade internacional. 


\section{HANS KELSEN E A NORMA FUNDAMENTAL DE DIREITO INTERNACIONAL}

Ao buscar uma justificativa para a vigência da norma de Direito Internacional, Hans Kelsen (2003) assinala que se se considera que o Direito Internacional é apenas parte integrante da ordem jurídica nacional representada como soberana, seu fundamento de vigência é a norma fundamental referida à Constituição eficaz.

Por outro lado, Kelsen aponta que quando o Direito Internacional é considerado não como parte integrante da ordem jurídica nacional, mas sim como uma única ordem jurídica soberana, supra ordenada a todas as ordens jurídicas nacionais, delimitando-as nos respectivos domínios de validade. Nesse sentido, se partiria não do primado da ordem jurídica nacional, mas do primado da ordem jurídica internacional.

É com base nessa segunda posição que se funda a possibilidade de existência do constitucionalismo universal, uma vez que nessa hipótese a norma de Direito Internacional representa o fundamento de vigência da ordem jurídica nacional. Nos dizeres de Hans Kelsen:

[...] uma norma do Direito Internacional geral reconhece a um indivíduo ou a um grupo de indivíduos o poder de, com base numa Constituição eficaz, criar e aplicar, como governo legítimo, uma ordem normativa de coerção. Ela legitima assim, para o domínio territorial de sua eficácia real, esta ordem jurídica como válida, assim como legitima como Estado, no sentido do Direito Internacional, a comunidade constituída através desta ordem legítima (KELSEN, 2003, p. 240).

Nesse caso, o fundamento de vigência do Direito Interno pode ser, segundo Kelsen, a norma fundamental do Direito Internacional, ou seja, o fundamento de vigência de determinado ordenamento jurídico nacional não reside numa norma pressuposta, mas sim numa norma jurídica positiva do Direito Internacional. A norma fundamental do Direito Internacional, por sua vez, é uma norma pressuposta e representa o pressuposto sob o qual as normas globalmente eficazes (as que regulam as condutas dos Estados entre si) são consideradas como normas jurídicas que vinculam os Estados.

O ponto de liame entre o pensamento kelsiniano e a possibilidade de se afirmar a existência do constitucionalismo universal reside justamente dentro dessa análise: se o fundamento de vigência das ordens jurídicas nacionais se encontra numa norma da ordem jurídica internacional, esta é concebida como uma ordem jurídica superior àquelas e, portanto, como a ordem mais elevadas de todas, como a ordem soberana, fatores esses inegavelmente presentes no constitucionalismo global. 


\section{CONSIDERAÇÕES FINAIS}

Tendo em vista os argumentos despendidos no presente artigo, cumpre notar que a história do constitucionalismo no âmbito do direito interno é marcada por um progressivo alargamento da esfera pública dos direitos.

Tal modelo constitucional na atualidade sedimenta, nos diplomas constitutivos nacionais, um importante conteúdo social e programático, pautado em premissas como a normatividade e superioridade da Constituição perante o ordenamento jurídico interno, características que marcam a transição da Constituição como diploma meramente político e dotado de pouca imperatividade para uma norma jurídica suprema de um Estado.

A citada transformação do Direito Constitucional na pós-modernidade, consolida o fenômeno da neoconstitucionalização do Direito, importando na propagação dos valores abrigados nos princípios e regras da Constituição por todo o sistema jurídico, por intermédio da aplicabilidade direta da Constituição a diversas situações.

O processo de universalização e internacionalização desses direitos, mormente os direitos humanos, é, contudo, um fenômeno que pode ser considerado extremamente recente na história do Direito, com delineamentos mais visíveis a partir do término da Segunda Guerra Mundial, evento que enseja uma intensificação da necessidade de atribuição de capacidade normativa pelos países aos organismos internacionais.

É dentro desse contexto que o constitucionalismo universal, deflagrado por meio do poder constituinte supranacional, erige suas bases e se apresenta como sendo um conjunto de princípios e normas institucionalizadas no âmbito internacional que regulam as relações de coexistência e cooperação entre Estados, limitando o poder e a soberania destes, que importam na irradiação desses valores abrigados em um diploma jurídico internacional por todo o ordenamento jurídico mundial.

Igualmente, reafirmando a possibilidade da existência do constitucionalismo universal, figuram os artigos art. $2^{\circ}, \S 6^{\circ}$, e 103, ambos da Carta da ONU, dispositivos que apontam para a superioridade hierárquica da Carta das Nações Unidas em relação a outros compromissos internacionais.

Sem embargos, em que pese tal subordinação formal ou hierarquia das fontes normativas propriamente ditas no Direito Internacional seja considerada pela doutrina 
majoritária como regida pelo princípio da coordenação, esta não tem o condão de inibir a existência de uma subordinação material aos preceitos institucionalizados pelo diploma internacional pactuado, principalmente no que diz respeito aos direitos humanos e as questões de segurança e paz internacionais.

Fundamenta-se referida subordinação material no argumento de que, conforme elucida Santi Romano, o conceito de organização não há de implicar necessariamente em uma relação de superioridade e de correlativa subordinação. Assim, o sistema jurídico internacional - por ser uma instituição/organização que pode existir sem a necessidade de subordinação formal nem a superioridade de normas ou Estados sobre outros no cenário internacional - está conectado juridicamente de forma unitária por um preceito (poder) impessoal objetivo (que marca a existência da comunidade internacional).

$\mathrm{O}$ ponto de liame entre o pensamento kelsiniano e a possibilidade de se afirmar a existência do constitucionalismo universal reside justamente dentro dessa análise: se o fundamento de vigência das ordens jurídicas nacionais se encontra numa norma da ordem jurídica internacional, esta é concebida como uma ordem jurídica superior àquelas e, portanto, como a ordem mais elevadas de todas, como a ordem soberana.

Conclui-se, portanto, que a defesa de um constitucionalismo que seja internacional, inobstante os desafios que permeiam a sua aceitação, está em formação e possui bases de sustentação, não só pelos diplomas jurídicos que se apresentam na contemporaneidade com disposições expressas acerca de tal possibilidade, bem como pelo anseio de grande parte da comunidade internacional, mormente a ocidental, em erigir preceitos e normas que vigorem e sejam respeitadas de modo universal.

\section{REFERÊNCIAS BIBLIOGRÁFICAS}

ACCIOLY, Hildebrando; SILVA, Geraldo Eulálio do Nascimento e; CASELLA, Paulo Borba. 2012. Manual de direito internacional público. 20ª ed. São Paulo, Saraiva.

AGRA, Walber de Moura. 2008. Curso de Direito Constitucional. Rio de Janeiro, Forense.

BARCELLOS, Ana Paula de. 2011. Neoconstitucionalismo, direitos fundamentais e controle das políticas públicas. Disponível em: <http://www.mundojuridico.adv.br/cgibin/upload/texto853.pdf>. Acesso em 18 de abril de 2016.

Revista Brasileira de Direito Internacional le-SSN: 2526-0219| Curitiba | v. 2 | n. 2 | p. 154 - 172 | Jul/Dez. 2016. 
BARROSO, Luis Roberto. 2008. Neoconstitucionalismo e constitucionalização do Direito. Disponível em: <http://jus.com.br/artigos/7547/neoconstitucionalismo-e-constitucionalizacaodo-direito/2>. Acesso em 15 de abril de 2016.

BOBBIO, Norberto. 2004. A Era dos Direitos. Rio de Janeiro, Elvisier.

BULOS, Uadi Lammêgo. 2009. Constituição Federal Anotada. São Paulo, Saraiva.

CAnotilho, J. J. Gomes. 2003. Direito Constitucional e Teoria da Constituição. Coimbra, Almedina.

CARVALHO, Kildare Gonçalves. 2006. Direito Constitucional: teoria do Estado e da Constituição. Belo Horizonte, Del Rey.

CUNHA, Paulo Ferreira da. Do Constitucionalismo Global. Disponível em: <www.esdc.com.br/245-Paulo_Ferreira_da_Cunha_(Do_Constitucionalismo_Global).pdf>. Acesso em 17 de junho de 2016).

DALlaRI, Dalmo de Abreu. 2009. Elementos de Teoria Geral do Estado. São Paulo, Saraiva.

FERRAJOLI, Luigi. 2007. A Soberania no Mundo Moderno. São Paulo, Martins Fontes.

KELSEN, Hans. Teoria Pura do Direito. Trad. João B. Machado. São Paulo: Martins Fontes, 2003.

LOEWENSTEIN, Karl. 1970. Teoría de la Constitución. $2^{\text {a }}$ ed. Barcelona, Ariel.

MAZZUOLI, Valerio de Oliveira. 2011. Curso de Direito Internacional Público. $5^{\text {a }}$ ed. São Paulo, RT.

PIOVESAN, Flávia. 2009. Direitos Humanos e o Direito Constitucional Internacional. 10ª ed. São Paulo, Saraiva.

REZEK, José Francisco. 2011. Direito Internacional Público: curso elementar. 13a ed. São Paulo, Saraiva.

ROMANO, Santi. 2008. O ordenamento jurídico. Florianópolis, Ed. Boiteux. 
SIMEÃO, Álvaro Osório do Valle. Soberania, Constitucionalismo e Mundialização do Direito. Disponível em: <http://jus.com.br/revista/texto/11403>. Acesso em 02 de maio de 2016.

TAYLOR, Paul; CURTIS, Devon. The Globalization of World Politics: an introduction to international relations. 3nd ed. Oxford: Oxford University Press, 2006.

VERGARA, Sylvia Constant. Métodos de Pesquisa em Administração. São Paulo: Atlas, 2005 . 